\title{
Prólogo
}

\section{Sujeto, subjetividad, identidad y sustentabilidad}

\author{
Enrique Leff
}

UNAM, Ciudad de México, México. Email: enrique.leff@gmail.com

\section{Antonio Elizalde}

Polis, Santiago, Chile. Email: aelizalde@ubolivariana.cl

Como fue señalado en la convocatoria para el presente número de Polis, éste fue convocado con el propósito de abrir un espacio para reflexionar sobre un privilegiado de las ciencias sociales: el sujeto y la subjetividad. Polis lo retoma en una indagatoria desde la crisis ambiental y en la perspectiva de la construcción de la sustentabilidad, donde el sujeto ecológico y los actores del ambientalismo adquieren nuevas dimensiones.

Esta reflexión sobre el sujeto no sólo descubre nuevas posiciones del sujeto, sino que desentraña la construcción epistemológica del sujeto que ha acompañado a la construcción del mundo moderno, donde la objetivación de la naturaleza a través de la ciencia ha sido acompañada por la configuración del imaginario del sujeto que se ha instaurado en la forma de una autoconciencia de la persona creada por el individualismo metodológico de la ciencia. Descubrimos así al sujeto no como una esencia del ser humano, sino como una construcción social que ha fundado y acompañado a la modernidad; pues el sujeto en la modernidad no es otro que el sujeto de la ciencia, la contraparte necesaria de la voluntad de conocer objetivamente la realidad que ha llevado a la objetivación del mundo.

El sujeto de la ciencia que abstrae sus valores, sentimientos e intenciones en la búsqueda del conocimiento objetivo es el crisol en el que se forjará el hombre sin atributos de Musil, el ser despojado de su ser. El sujeto autoconsciente que nace como soporte del mundo objetivo va convirtiéndose en un efecto-sujeto, en un ente configurado y determinado por las estructuras objetivas en las que se inscribe, y va despojándose de su mítica libertad originaria. El sujeto económico no es el empresario innovador, sino el trabajador despojado de su empleo; el sujeto político es el sujeto atrapado por la burocracia; el sujeto psicológico no es el yo autoconsciente, sino el sujeto inconsciente de las formaciones del inconsciente.

El sujeto ecológico no emerge en este escenario de la modernidad iluminado por una consciencia emancipadora de la crisis ambiental. Los 
sujetos se van emancipando de su condición de sujetos a través de una desconstrucción de la racionalidad que los ha configurado. El sujeto no se emancipa por una nueva lucidez, por una autorreflexión sobre sí mismo, como quisieran los sociólogos de la modernidad. No sólo adoptan nuevas posiciones subjetivas. La emancipación del sujeto implica romper el espejo en el que se refleja la autoconciencia distorsionada de su ser. De la ipseidad del yo, la ética posmoderna se abre a la ética de la otredad. El sujeto se vuelve a su concepción como persona. El sujeto, en su conciencia individualista se abre de la autoafirmación del yo a la concepción de un nosotros, a la idea de un ser colectivo que se conforma junto con la configuración de los derechos ambientales emergentes en la reapropiación de los bienes comunes de la humanidad, de los derechos comunitarios, donde el sujeto ecológico transita de una ecología de la mente, de posiciones subjetivas reconfiguradas funcionalmente en las redes de interrelaciones del mundo ecologizado, a la formación de actores sociales en la reapropiación de bienes comunes, de valores comunes pero diferenciados en la construcción de sustentabilidades diversas y de un mundo diverso.

En el contexto de la construcción de un mundo constituido por una relación de seres culturales, el sujeto y su subjetividad se resignifican en torno a la constitución de nuevas identidades colectivas. En este sentido, las posiciones subjetivas salen del encierro de su individualismo para proyectarse hacia la construcción de los nuevos actores sociales en la construcción de un mundo sustentable.

En respuesta a esta convocatoria tuvimos una excelente acogida lo que nos obligó a dejar fuera de este número una cantidad importante de muy buenos trabajos presentados. Pero así es la tarea de convocar y editar, y finalmente discriminar. Creemos haber seleccionado una óptima muestra de lo que es posible aportar sobre el tema convocado.

Se inicia el Lente de Aproximación de este número con el texto de Gilberto Aranda y Sergio Salinas titulado "Cronotopos y parusía: las identidades míticas como proyecto político”, en el cual tratan el tema de las identidades sociales y de los mitos políticos. Señalan la importancia de valorar el pasado en los procesos de identificación social, ya que dicha valoración ha posibilitado que distintos actores sociales, en diferentes momentos históricos, hayan hecho uso del pasado para estructurar las ideologías que sustentan procesos de identificación y sus propios proyectos políticos. Sostienen que los mitos políticos están compuestos por un lado por la política simbólica y por otro lado por la memoria colectiva, y que es necesario que la politología los estudie y considere.

Nazareno Bravo en su artículo, “Movimientos Sociales y acción colectiva como bases de la filosofía latinoamericana”, retoma la propuesta de Arturo Roig en torno a la existencia de una moral de la protesta en la filosofía latinoamericana, haciendo alusión a una tradición moral desarrollada en América Latina desde sus inicios en estrecha vinculación con movimientos de liberación y movilizaciones sociales de los sectores subal- 
ternos. Considera la acción colectiva y las disputas por la identidad como estrategias simbólicas que forjan nuevas identidades y actores colectivos, analizando los fenómenos colectivos emergentes en Argentina, para entenderlos como avances hacia la conformación de un pensamiento latinoamericano que busca la construcción de nuevas identidades emancipatorias.

Noelia Enriz en su texto "Identidades en tensión, lo indígena y lo nacional en las experiencias cotidianas mbyá", trata el tema de lo identitario en tanto modo de ser y el territorio como el lugar "donde podemos ser"; busca problematizar el modo en que las identidades nacionales e indígenas se han vinculado y consolidado en el caso argentino, estudiando las poblaciones guaraníes de la provincia de Misiones. Reflexiona sobre la tensión histórica de estas identidades y discute la forma como actualmente los estados se vinculan con las identidades indígenas a través de políticas específicas.

Dimas Floriani, José Edmilson de Souza Lima, José Julio Nunes Ferreira y Marcelo Stein de Lima Sousa presentan un artículo titulado "Para pensar la subjetividad en el debate del socioambientalismo", en el cual analizan la importancia del ejercicio del filósofo social e intentan localizar el origen del debate moderno sobre la «subjetividad» en el pensamiento social y filosófico. Partiendo de Kant, revisan el debate de diversos autores como Badiou y Zizek, Castoriadis, Touraine, Serres y Stengers, lo cual les permite cuestionar y proponer la adaptación de las prácticas de producción de conocimiento, y el discurso científico.

"Sujetos colectivos en búsqueda de sustentabilidad pesquera: relatos de los miembros de una comunidad de pescadores artesanales, V región, Chile” es un artículo de Violeta Glaría que da cuenta de la constitución identitaria de los pescadores artesanales, como actores sociales en la búsqueda de sustentabilidad y en el diseño de estrategias que aseguren niveles de capturas por debajo de la tasa de regeneración de cada especie y regulaciones de los aparejos de pesca que signifiquen el menor daño posible a los ecosistemas marinos. Señala que la legislación que regula el sector vence en 2012 y que los pescadores artesanales deberían tener un rol significativo en la gestión de la administración pesquera.

José Gutiérrez-Pérez presenta un texto titulado "Narrativas virtuales para la reconstrucción del Sujeto Ecológico de nuestro tiempo" que ofrece un análisis crítico del impacto contemporáneo que está teniendo la proliferación de una Educación Ambiental de nueva generación apoyada por herramientas tecnológicas virtuales en la construcción de una renovada identidad profesional y de un sujeto ecológico postmoderno en continua reconstrucción, reciclado e influido por la tecnología en su práctica laboral ordinaria y en su vida cotidiana como ciudadano ambientalmente comprometido. Se acerca fenomenológicamente al nuevo sujeto ecológico, a un nuevo concepto de educador ambiental y de Educación Ambiental que se perfila empujado por avances tecnológicos, realidades virtuales, redes sociales y medios de comunicación. 
Enrique Leff, en su texto titulado "El Desvanecimiento del Sujeto y la Reinvención de las Identidades Colectivas en la Era de la Complejidad Ambiental”, intenta desconstruir el sujeto que derivó en el individualismo metodológico de la ciencia y llevó a la objetivación de la naturaleza en la construcción de la racionalidad de la modernidad. Sostiene que los sujetos se van emancipando de su sujeción por la desconstrucción de la racionalidad que los ha capturado y en un proceso de reinvención de las identidades en la complejidad ambiental. Más allá de la hermenéutica del yo y la intersubjetividad fundada en una racionalidad comunicativa, la ética posmoderna confronta la individualidad con la otredad. El sujeto vuelve al ser como persona. El ser individual da lugar a un nos-otros, a la identidad del ser colectivo, de un ser cultural. Así, emergen los nuevos actores sociales guiados por una racionalidad ambiental hacia la construcción de un mundo sustentable, llevado hacia la heterogénesis de la diversidad por un diálogo de saberes, en una ética de la otredad y una política de la diferencia.

A su vez, Sandra Mara Maciel-Lima, presenta un trabajo titulado "El sujeto posmoderno en la cultura contemporánea”, en que busca identificar algunos componentes y constituyentes del sujeto posmoderno para tratar de responder a la siguiente pregunta: ¿quién es este hombre posmoderno? Recurre a diversos marcos teóricos que buscan elementos constitutivos y constituyentes de este nuevo proyecto, y concluye que éste considera una visión no lineal del progreso, incorpora valores reconocidos por la sociedad y una moralidad apuntando a ser reconocidos por «otros», enfatiza la autonomía discursiva y avanza hacia una epistemología de la alteridad, promoviendo una radicalización de la subjetividad.

Graciela Mazorco Irureta titula "La descolonización en tiempos del Pachakutik” el artículo en que presenta la descolonización como un proceso de desconstrucción de la alienación y subordinación del ser humano, y de simultánea construcción de un individuo autónomo y activo para edificar "otro mundo posible", alertando sobre el riesgo recolonizador inserto en las propias visiones descolonizadoras, pues reproducen las dicotomías etnocéntricas entre colonizador y colonizado, o entre indio y occidental, potenciando los códigos que nos recolonizan diariamente. Propone así un nuevo paradigma filosófico que responda a una cosmovisión alternativa y nos provea de un lenguaje nuevo.

María del Rosario Millán en su texto titulado "La figuración del Frente Costero para la ciudad de Posadas" aborda el proceso de figuración del nuevo frente costero para la ciudad de Posadas, Misiones, Argentina, debido a la elevación de las aguas del río Paraná por la formación del embalse de la represa Yacyretá. Tomando en cuenta diversos aspectos vinculados con la formación discursiva sobre el desarrollo, movilizados para la implementación de políticas urbanas, plantea el problema de la articulación entre el plano discursivo y el plano físico de las transformaciones urbanas.

En un texto de autoría de Leonora Reyes, Rodrigo Cornejo, Ana Arévalo y Rodrigo Sánchez titulado "Ser docente y subjetividad histó- 
rica en el Chile actual: discursos, prácticas y resistencias” se da cuenta de una instancia de trabajo colectivo generada con profesores y profesoras de aula, que persiguió rastrear el proceso de construcción de nuevas subjetividades docentes, para así dar cuenta de las actuales condiciones en que es desempeñada la docencia y proponer otras formas de ser docente. El texto habla de la transformación del sujeto educativo hacia la constitución de la identidad colectiva del educador en un compromiso docente por cambiar la realidad educativa de pasar de la crítica a las construcciones colectivas respecto del quehacer docente en una apuesta común, en un tránsito del sujeto-sujetado hacia la construcción de identidades emancipatorias.

"Heterotopías Urbanas: Espacios de poder y estrategias socioespaciales de los Sin Techo en Río de Janeiro" se titula el último trabajo incluido en esta sección. En este artículo Tatiana Tramontani Ramos vincula las luchas de los movimientos de las personas sin hogar en Río de Janeiro y la idea de heterotopía desarrollada por Michel Foucault. Señala que estas luchas pueden identificarse como contribuciones a la creación y mantenimiento de enclaves insurgentes en la ciudad, esto es, heterotopías urbanas. Espacios concretos y reales creados, definidos y reproducidos a partir de relaciones de poder localizadas. A diferencia de las utopías que serían espacios inmateriales, ilusorios, idealizados y posiblemente inalcanzables, las heterotopías serían espacios concretos y reales, utopías efectivamente realizadas que manifiestan lo que es necesario, justo, factible y posible, para sobrevivir en la ciudad.

La sección Cartografías para el Futuro incluye el trabajo "La intersubjetividad como sintonía en las relaciones sociales. Redescubriendo a Alfred Schütz", texto en que Magaly Cabrolié aborda una relectura de un trabajo de Alfred Schütz que introduce la idea de intersubjetividad como sintonía en las relaciones sociales. Explora así la dimensión temporal, el cara a cara y la sincronización con el Otro, instalando la posibilidad de comprensión de los procesos intersubjetivos, en la perspectiva del reconocimiento de la alteridad (Levinas) y se pregunta si es posible, en contextos excluyentes, avanzar hacia la constitución de sintonía entre sociedad y Estado.

A continuación se presenta el artículo titulado "Intelectuales y científicos en América Latina: La importancia de los temas Subjetividad, Calidad de Vida y Riesgo" de autoría de Leila da Costa Ferreira y Sônia Regina da Cal Seixas, propone dos contribuciones al interesante debate sobre la calidad de vida, la subjetividad y el riesgo en el área de Medio Ambiente y Sociedad. Apuntan así hacia nuevas matrices culturales basadas en una epistemología de la alteridad, que promueve una radicalización de la subjetividad, de nuevos grupos, nuevas voces, nuevas interpretaciones de la historia, de las relaciones sociales y del sujeto que emerge de las interacciones sociales, incorporando valores reconocidos por la sociedad y manteniéndose actualizado en los patrones de conducta necesarios para ser reconocido por el otro, ese otro inscrito en el mismo espacio social. 
Finalmente esta sección incluye el texto de Hugo Zemelman que lleva por título "Sujeto y subjetividad" en que aborda el desafío de una conceptualización de la realidad socio-histórica que rompa con la separación entre lo real como externalidad y el sujeto. Señala, que ese desafío pasa por redefinir la idea de objetividad. Habría que encontrar un concepto de subjetividad constituyente que no sea reducido a variables psicológicas o a simple expresión de procesos macrohistóricos. Metodológicamente destaca el contrapunto entre contenidos teóricos permanentes y la transitoriedad de los sujetos. Finalmente sostiene que para armonizar desarrollo humano y desarrollo social son necesarias relaciones sociales que no impliquen dominación económica ni política. Y se pregunta: ¿Es que el capitalismo se esconde detrás de la democracia, por lo que ésta, en su propio nombre, se niega así misma?

La sección Proyectos y avances de investigación incluye los siguientes artículos: "La medicina social y las experiencias de atención primaria de salud (APS) en Latinoamérica: historia con igual raíz” de Giovanni Apráez Ippolito; "Las perspectivas de la democracia sindical en Italia: el referéndum de los trabajadores” de Davide Carbonai; “América Latina: emergencia de un re-diseño institucional” de Diosey Ramón Lugo-Morin; "Crisis del sistema capitalista mundial: paradojas y respuestas" de Humberto Márquez Covarrubias; "El teatro: acercamiento a la estética política” de Rubén Mendoza; “Gobernabilidad neoliberal y movimientos indígenas en América Latina” de Rodrigo Navarrete; "Estado de derecho y desobediencia civil” de Carlos Fabián Pressaco; y finaliza esta sección con el artículo "Condiciones y experiencias de trabajo en la sala de venta de un supermercado. Explorando los procesos de flexibilización laboral en el sector del retail en Chile” de Antonio Stecher, Lorena Godoy y Juan Pablo Toro.

En la sección Comentarios y reseñas de libros se presenta la reseña escrita por Esteban de Manuel Jerez, del libro Universidad comprometida de Vicente Manzano.

Finalmente, como Dossier, se incluye por su relevancia el texto del II Pronunciamiento Latinoamericano por una Educación para Todos, producido en Buenos Aires en septiembre de 2010. 